\title{
CIRURGIA GINECOLÓGICA: TRABALHO EM GRUPO VISANDO O PREPARO PARA INTERNAC̣ÃO
}

Celi Aparecida Thiago Maia*

Marilene Colodo**

Ianê Nogueira do Vale***

\begin{abstract}
RESUMO - Por ocasião do agendamento da cirurgia ginecológica, mulheres são atendidas em grupo por uma enfermeira e uma assistente social visando o preparo pré-operatório já no período que antecede a internação. A abordagem grupal valorizando o diálogo e o atendimento das ansiedades das clientes são a tônica deste trabalho.
\end{abstract}

ABSTRACT - When the scheduli for gynecological sugery is being made, the women are attended in groups, by a nurse and a social worher, with a view to pre-op. preparation in the period before admission. The group approch, emphasizing dialogue and dealing with the anxieties of the clients, is the characteristic of this work.

\section{INTRODUC̣ÃO}

Toda pessoa que vai se submeter a uma cirurgia, carrega uma grande expectativa em relação a o processo cirúrgico em si, assim como a internação, recuperação, etc... Para MARTINEZ (1971), qualquer intervenção cirúrgica desperta ansiedade, porque significa um perigo que ameaça a integridade do indivíduo.

Em se trátando de cirurgia ginecológica, o fato de estar relacionado com os órgãos sexuais e reprodutores, traz uma gama de preconceitos e tabus que vem se juntar às dificuldades próprias de uma cirurgia.

Todo comportamento de ansiedade, nervosismo e medo, pode ser minimizado se o paciente puder compreender e conhecer um pouco do processo pelo qual vai se submeter. 0 estresse da doença e da própria cirurgia e anestesia, serão melhores superados quanto melhor o paciente compreender a importãncia de sua cooperação e participação. (CASTELLANOS et alii, 1975; JOUGLAS \& SALZANO, 1981).

Em nossa vivência prática temos percebido que os pacientes passam pelos serviços de saúde, são atendi- dos por médicos, enfermeiros e assim mesmo não sabem nada do que está acontecendo consigo. No serviço em que atuamos, recebemos pacientes que vêm marcar a sua cirurgia, e não tem a menor idéia do seu diagnóstico e nem mesmo do tipo de cirurgia a que vão se submeter. É como se o destino de sua vida não lhe dissesse respeito ou também que o paciente não tem condições intelectuais ou emocionais de entender os fatos. No entanto, os pacientes têm o direito de receber informações completas, que sirvam de base para que possam lidar com a realidade e não serem por ela abafados (CASTELLANOS et alii, 1975).

Numa breve revisão bibliográfica, pudemos perceber que a falta de preparo de pacientes para a cirurgia, tem sido objeto de preocupação de vários setores. A visita pré-operatória de enfermagem, tem sido apontada como de suma importãncia para contribuir com o bem-estar do paciente e até mesmo com o sucesso da cirurgia (CASTELLANOS \& BIANCHI, 1986; 1984; JOUGLAS \& SALZANO, 1981).

A importãncia da visita pré-operatória é indiscutível, mas também vemos a necessidade de ampliar esse

\footnotetext{
* Enfermeira Habilitada em Saúde Pública na Escola de Enfermagem da USP de Ribeirão Preto. Supervisora do Ambulatório de Ginecologia - CAISM - UNICAMP.

** Assistente Social do Ambulatório de Ginecologia do CAIMS - UNICAMP.

*** Enfermeira Especialista em Obstetrícia. Auxiliar de Ensino do Departamento de Enfermagem da FCM. Diretora do Serviço de Neonatologia do CAISM - UNICAMP.
} 
preparo. 0 tempo de internação antes da cirurgia é muito pequeno e o paciente na realidade já está presente no sistema hospitalar por ocasião do diagnóstico e dos exames laboratoriais necessários. 0 preparo para cirurgia a nosso ver deve começar no ambulatório, e que se estabeleça um sistema de informações entre ambulatório, unidade de internação e centro cirúrgico (SALZANO, 1986) para que os dados sobre o paciente em relação à cirurgia sejam mais completos, além de estar o paciente em várias ocasiōes em contato com profissionais que possam estar atendendo as suas necessidades.

Este trabalho pode contribuir para a individualização do atendimento e principalmente a visão do paciente fora do contexto hospitalar, o que vem de encontro com a recomendação de RICHTER citado por .JOUGLAS \& SALZANO (1981), "não olhemos para os pacientes como se fossem um objeto qualquer, como se tivessem sido sempre pacientes ou como se fossem pacientes para todo o sempre. Devemos pensar onde eles estavam dias antes? Onde estarão depois? Como a operação neles realizada, irá figurar na sua experiência total de vida?".

Não pretendendo ser sonhadoras, acreditamos ser viável a realização de um trabalho de tal alcance. É necessário que se insista na atuação do enfermeiro marcada mais por atividades assistenciais do que burocráticas. Só estaremos valorizando a atuação do enfermeiro quando soubermos colocar as devidas prioridades centradas no atendimento ao paciente. Sabemos que tecnicamente em nossa realidade, o enfermeiro pode ser substituído pelo auxiliar de enfermagem. No entanto nenhum profissional da equipe, por uma questão de informação, pode substituir o enfermeiro na prática educativa, dada a complexidade que envolve a educação.

Muitos são os trabalhos que evidenciam a deficiência de atuação do enfermeiro na orientação e educação do paciente por diversos motivos (ALMEIDA, 1985; NOGUEIRA, 1979; SECAF, 1977). Quanto a pacientes cirúrgicos, RODRIGUES (1984) demonstrou em sua pesquisa que "a orientação para cirurgia quando houve foi feita de maneira assistematizada, por meio de palavras soltas ou conversações fragmentadas, sendo ele deixados com muitas dúvidas sobre o que iria acontecer no trans e no pós-operatório". CARVALHO (1984), percebeu pouca participação do enfermeiro na orientação dos pacientes e a tendência em delegar o preparo do cliente à assistente social.

Além da importância que deve ser atribuída à orientação e educação de pacientes já citadas anteriormente, é necessário que também pensemos em como orientar e educar esse paciente.

Já foi apontado por ALMEIDA (1979) e GERMANO (1983) o atrelamento da enfermagem à ideologia dominante o que a nosso ver influencia diretamente a nossa postura profissional, principalmente a prática educativa.

É nos difícil olhar a paciente como um ser social, pensante, banhado em historicidade, com direito à educação e saúde. É nos difícil olhar o paciente como um ser que traz uma bagagem de experiência, de credos, de tabus, etc... que são vitais para ela naquele momento e que podem ser respeitados sem prejudicar a qualidade de assitência que ela precisa receber. A nossa prática educativa quando realizada, é autoritária e absoluta. É reinterativa, não tendo a preocupação de despertar a reflexão no outro.

Neste trabalho onde nos propusemos desenvolver um programa educativo com mulheres que se submeterão à cirurgia ginecológica, temos a preocupação de "através da problematização do homem-mundo, ou do homem em suas relações com o mundo e com os homens, possibilitar que estes aprofundem sua tomada de consciência da realidade na qual e com a qual estão" (FREIRE, 1980).

As mulheres chegam ao ambulatório e trazem sua realidade. Tentamos entendê-la e muitas vezes na nossa limitação, existe outra mulher em condições materiais de existência semelhante que pode ajudá-la a olhar de frente a sua realidade para poder transformá-la.

O conteúdo de informação que são trabalhadas no grupo surgiu do contato com as próprias mulheres, e só são expostos no momento em que se percebe a dívida e conseqüentemente necessidade de ouvir o que temos a dizer. Permeando o contato, tem-se a preocupação de que as mulheres saibam que somos profissionais ganhando para desempenhar aquela função e que a utilização daquele serviço é um direito seu.

É necessário que alcancemos o domínio da técnica e do processo educativo, mas isso não é suficiente para o desenvolvimento do trabalho. É fundamental que entendamos a importância da própria criação de uma nova atitude, a atitude do diálogo, uma relação horizontal necessária entre dois sujeitos (FREIRE, 1985).

\section{OBJETIVOS}

2.1. Organizar um programa educativo;

2.2. Minimizar o impacto da internação e da cirurgia sobre as mulheres que se submeterão a cirurgia eletiva; 2.3. Oferecer informacões sobre os recursos de saúde da comunidade.

\section{METODOLOGIA}

\subsection{Histórico:}

O CAISM (Centro de Assistência Integral a Saúde da Mulher) abrange $o$ atendimento de mulheres do município de Campinas e toda a região. Possue recursos técnicos e materiais para atendimento especializado e se propõe a atender a mulher em todos os seus aspec- 
tos como um ser integral. A equipe de saúde è composta entre outros de médicos, enfermeiros, assistentes sociais e psicólogos que juntos podem garantir um atendimento que abrange todos os aspectos que envolvem a vida de cada cliente.

O ambulatório de cirurgia ginecológica, parte do Ambulatório de Ginecologia de Especialidades, atende todas as mulheres que internam para cirurgias eletivas. São encaminhadas do Ambulatório de Ginecologia Geral das Clínicas e Ambulatório de Reprodução Humana.

Essas mulheres são atendidas em três momentos neste ambulatório: por ocasião da marcação da cirurgia, quando internam, e no retorno de revisão da cirurgia, sendo que para revisão só retornam, neste ambulatório, as que tem resultado de anátomo patológico.

O programa educativo em questão teve início no mês de novembro de 1986 .

\subsection{Caracterização da clientela}

As mulheres em sua maior parte são carentes de recursos materiais e de entendimento das questões de saúde que as envolve. Procedem predominantemente de bairros periféricos de Campinas e cidades circunvizinhas. Muitas delas estão na espectativa de verem solucionados problemas que há muito as incomodam. A idade média varia entre 25 a 40 anos.

\subsection{Desenvolvimento do Programa}

Inicialmente as mulheres eram atendidas individualmente pela assistente social do ambulatório, visando fornecer informações para a internação. Com o aumento da demanda e pela valorização da abordagem grupal, as orientações passaram a acontecer em pequenos grupos.

No decorrer das primeiras reuniões, a assistente social solicitava da enfermeira do ambulatório esclarecimento de dúvidas das clientes, relativas à cirurgia. Foi então que se sentiu a necessidade de um trabalho conjunto entre a assistente social e a enfermeira.

A cada segunda-feira as clientes são encaminhadas ao ambulatório para agenciamento da cirurgia com o médico. Antes da consulta, as mulheres são reunidas para orientação em grupos de no máximo oito. Nesta ocasião o laudo cirúrgico e os exames pré-operatórios já estão ef etuados.

A princípio as reuniōes planejadas para meia hora de duração seguia a seguinte dinâmica: o conteúdo previamente estabelecido pelas referidas ;rof issionais era "despejado" sobre o grupo. Embora o conteúdo tenha sido estabelecido a partir de nossa vivência com as mesmas e considerado por nós como de grancle importância, percebíamos que o tempo era suficiente para nós mas que as mulheres se mostravam desatentas e até mesmo com conversas paralelas.

Ao discutirmos o prohlema entre nós e com a participação da supervisora de enfermagem do setor na época, passamos a atuar com uma outra dinãmica, adotando a abordagem problematizadora.

Procuramos iniciar o grupo perguntando de uma forma geral: 'Vơcês estão aqui para marcar uma cirurgia. Como estão se sentido?'. De pronto sentimos uma mobilização e várias questões começaram a eclodir. Algumas perguntas são respondidas pelo próprio grupo e quando se faz necessário por uma das coordenadoras. Quando sentimos a necessidade de abordar algum ponto, procuramos questionar o grupo, de tal forma que praticamente todos os pontos que envolvem a problemática de uma internação para cirurgia sejam discutidos.

Geralmente o conteúdo básico é comum aos grupos e pode ser assim descriminado: a nutrição précirúrgica; esclarecimento quanto ao tipo de cirurgia que vai ser realizada incluindo o preparo pré-trans e póscirúrgico; os profissionais que compõem a equipe de saúde; documentação necessária a internação; recursos da comunidade quanto a remoção de pacientes; preparo da família quanto a ausência da mulher, causada pela internação; programa de doação de sangue, discussão sobre o direito à assistência à saúde e os re('ursos da comunidade.

I)urante a reunião utilizamos material audiovisual quando se faz necessário. As mulheres recebem folhetos contendo as orientações básicas para a internação.

\section{DISCUSSÃO DO PROGRAMA}

Neste tópico não é nossa intenção descrever os conteúdos desenvolvidos nos grupos, mas as questões de maior relevância por nós vivenciadas, sempre levando em consideração a proposta de uma dinâmica problematizadora.

Ao iniciarmos o grupo perguntando as mulheres "o que estão sentindo?" permitimos o livre acesso de suas colocações. Estas vão desde um tímido "estou bem" até "eu tenho medo da cirurgia e da anestesia", as mulheres têm a chance de expressar seus temores e compartilhar com outras que estão em situaçâo semelhante.

Buscamos a partir de seus relatos iniciais um diálogo sobre a internação. E o medo da anestesia é um dado sempre levantado, procuramos, então, abordar com o grupo experiências anteriores que possam ser relatadas. É um assunto difícil de ser discutido e não é feito do ponto de vista didático. A nossa intenção não é aprendizado, mas falar sobre um problema emergente e propiciar a diminuição do stress.

A assistente social geralmente questiona o grupo sobre como esclarecer a família para a visita, percebemos que esta mulher, cliente em outros momentos neste serviço, não sabe informar o nome do hospital onde permanecerá internada. 
E a medida que avançamos no grupo, fica claro que a falta de informação não termina no desconhecimento do nome do serviço. Ao indagarmos sobre a cirurgia, ocorre que, embora portadoras do laudo de internação, muitas não sabem o seu diagnóstico e a cirurgia que se submeterão. Apesar de várias vezes estas dúvidas serem esclarecidas no grupo, incentivamos as mesmas a conversarem com a equipe médica procurando uma interação maior do profissional com a cliente.

Em relação ao diagnóstico médico convivemos com um problema ainda sem solução. Por um lado acreditamos ser esta uma tarefa do médico e por outro lado nos sentimos insatisfeitas, quando mesmo após a consulta a cliente não está esclarecida de que vai ter um orgão, como por exemplo o útero, estirpado. Pode, às vezes, saber o nome da cirurgia, mas não conhece o seu significado e assim esta dúvida gera fantasias e medo.

Considerando a situação econômica da população por nós atendida um problema sempre levantado é "quanto tempo ficarei internạda?". Tentamos na medida do possível não criar expectativa de alta, falamos sobre o tempo médio de internação. Procuramos, também, ver esta mulher enquanto ser social que terá problemas em rela(cäo a ('asa, marido e filhos e precisa fazer uma programação para vir ao hospital se internar. Falamos sobre as diferenças pessoais e que refletem no processo de recuperação, sobre a necessidade de se preparar inclusive com alimentação adequada sempre levando em consideração os seus recursos materiais.

Ainda lembrando a população em questão, a grande maioria, não possui recursos próprios para sair do hospital na ocasião da alta. Necessita dos recursos da comunidade. Este é um direito, mas, a mulher é informadla de que permanecerá mais tempo no leito porque as conduções são destinadas para atender a um número grande de pessoas.

Outra dúvida que é abordada pelas mulheres se refere ao repouso pós-cirúrgico no caso de perineoplastia sugerimos aproximadamente quarenta dias sem atividade física excessiva e sem relação sexual vaginal. Nessa ocasião não raro aparece as questões "quem vai fazer os serviços de casa?", "minha patroa não vai permitir tanto tempo de repouso", "meu marido não vai agüentar" e outras dizem "se fosse meu marido só mandiando para fora do quarto", "às vezes ele pode procurar outra, dá para entender". Não podemos resolver estes problemas, mas conversamos sobre eles. O próprio grupo sugere que procure algum conhecido ou da família para ajudar nas atribuiçōes domésticas. Falamos das alternativas de satisfação sexual valorizando a afetividade.

$\mathrm{E}$, assim, muitas questões são levantadas: a amamentação durante o processo de internação, o que trazer para se internar, o horário e etc. Nestas reuniōes, ainda detectamos não raramente, alguns problemas que necessitam de encaminhamento a outros profissionais ou atendimento individual, que pode ser feito após o grupo.

Percebemos que com a mudança de dinâmica o grupo enriqueceu, pois, se estabeleceu um processo de troca de experiências e expectativas. As mulheres não recebem uma aula pronta, participam procurando as respostas. Nenhum grupo se repete, apesar do assunto girar em torno dos mesmos temas. É sempre novo porque pela nossa forma de abordagem são as mulheres que decidem os caminhos a serem seguidos.

\section{CONCLUSÃO}

Em se tratando de um trabalho recente onde a abordagem educativa tem um caráter predominantemente qualitativo, não dispomos ainda de instrumento avaliativo adequado.

Sabemos que temos ainda muito o que aprender, e também reconhecemos a necessidade de se adotar uma forma de registro que transpareça a riqueza de dados colhidos nas reuniōes sobre cada cliente, que possam ser utilizados pela unidade de internação e centro cirúrgico. Temos a pretenção de, resolvendo esses problemas, alcançar uma assistência de enfermagem mais integral.

Gostaríamos também de registrar que esse trabalho muito nos gratifica e tem contribuído para o nosso desenvolvimento profissional.

\section{REFERÊNCIAS BIBLIOGRÁFICAS}

1. ALMEIDA, M.C.P. Estudo do saber de Enfermagem e sua dimensão prática. Rio de .Janeiro, Escola Nacional de Saúde Pública da Fundação ()swaldo Cruz, 1984. 1979p. tese dout.

2. AlMEIIDA, M.L.M. A prática educativa do Enfermeiro. Curitiba, UFP, Escola de Enfermagem, 1985. 172p. Diss Mestr.

3. CARVALHo, Z.M.F. (Orientação de Enfermagem - fator importante no ajustamento das mulheres mastectomizadas: contribuição à assistência de enfermagem. Revista Brasileira de Enfermagem. Brasília, 37(:3/4): 157-64, jul./dez. 1984

4. CASTELLAN(OS, B.E.P. et alii. Centro cirúrgico: subsistema do macro sistema hospital. Enfermagem Novas Dimensões, São Paulo, I (:3): 1:2(;-29, jul./ago. 1975).

5. CASTELLAN()S, B.E.P. \& BIANCHI, E.R.F. Visita préoperatória de Enfermagem: opinião dos alunos de graduação quanto a este procedimento. Revista Paulista de Enfermagem, Sào Paulo, 6 (4): 157-(i), out./dez. 1986.

6. ('ASTELLAN()S, B.E.P. \& BIAN('HI, E.R.F. V'isita pré-operaloria do Enfermeiro da unidade de centro cirúrgico: marcos referenciais para o seu ensino no curso de gradıação de Enfermagem. Revista Paulista de Enfermagem, São Paulo, 4 (1): 10-14, jan./mar. 1984 .

7. FREIRE, P Educaçăo c mudança. 10) ed. Riode Janeiro, Paz (e terra, 1985. 15)p.

8. FREIRE, P. Extensão ou comunicação? Rio de Janeiro, Paz e Terra, 198(). 9:3p.

9. (iERMAN(), R.M. Educaçào e ideologia da Enfermagem no Brasil. São Paulo, Cortez, 198:3. 118p.

\|1. J()UGLAS, V.M.G. \& SALZAN(), S.A.T. Planejamento de uma ficha pré-operatória de Enfermagem. Revista da Escola de Enfermagem LSP, São Paulo, 15(1):5-16, 1981.

11. MARTINEZ, J.E. Enfoque psicossomático na cirurgia. In: KATZ, E. Pre y posoperatório normal e patológico. Buenos Aires, Universitária, 1971. p.921-39. 
12. NOGUEIRA, M.J.C. A Enfermagem comunitária no currículo do curso de graduação em Enf ermagem: Parte II. Revista da Escola de Enfermagem USP. São Paulo, 13(2): 171-81, ago. 1979 .

13. RODRIGUES, A.I. O paciente no sistema centro cirúrgico - um estudo sobre percepções e opiniões de pacientes em relação ao período trans-operatório. Revista da Escola de Enfermagem USP, São Paulo, 18 (2): 163-76, ago. 1984.
14. SALZANO, S.D.T. Os problemas dos pacientes detectados pela Enf ermeira durante a recepção no centro cirúrgico. Revista Paulista de Enfermagem, São Paulo, 6(2):66-77, abr./jun. 1986.

15. SECAF, V. Atividade educativa da Enfermeira - preparo e desempenho. São Paulo, USP, Escola de Enfermagem 1977.110 p. Diss. mestr. 